\title{
Impaired glucose-insulin metabolism in males with obstructive sleep apnoea syndrome
}

\author{
N. Meslier*, F. Gagnadoux*, P. Giraud", C. Person*, H. Ouksel*, T. Urban*, J-L. Racineux*
}

Impaired glucose-insulin metabolism in males with obstructive sleep apnoea syndrome. N. Meslier, F. Gagnadoux, P. Giraud, C. Person, H. Ouksel, T. Urban, J-L. Racineux. (C) ERS Journals Ltd 2003.

ABSTRACT: The aim of this cross-sectional study was to evaluate the frequency of type-2 diabetes and impaired glucose tolerance (IGT) in a large clinic-based male population presenting various degrees of obstructive sleep apnoea syndrome (OSAS) and to analyse the relationship between OSAS and glucose-insulin metabolism.

Male patients $(n=595)$ with suspected OSAS underwent both nocturnal polysomnography and a 2-h oral glucose-tolerance test with measurements of fasting and postload blood glucose and plasma insulin. Insulin sensitivity was evaluated by the ratio of fasting glucose to fasting insulin.

OSAS was diagnosed in 494 patients, while 101 patients were nonapnoeic snorers. Type-2 diabetes was present in $30.1 \%$ of OSAS patients and $13.9 \%$ of nonapnoeic snorers. IGT was diagnosed in $\mathbf{2 0 . 0} \%$ of OSAS patients and $13.9 \%$ of nonapnoeic snorers. Fasting and postload blood glucose increased with severity of sleep apnoea. Insulin sensitivity decreased with increasing severity of sleep apnoea. In addition to body mass index and age, the apnoea/hypopnoea index independently influenced postload blood glucose and insulin sensitivity.

The authors conclude that in a clinic-based sample of patients, obstructive sleep apnoea syndrome is associated with a high frequency of type- 2 diabetes and impaired glucose tolerance. The relationship between sleep-disordered breathing and impaired glucose-insulin metabolism is independent of obesity and age.

Eur Respir J 2003; 22: 156-160.
*Sleep Disorders Unit, Dept of Pneumology, University Hospital and \# Endocrinology, SaintSauveur Clinic, Angers, France.

Correspondence: N. Meslier

Unité de Pathologie du Sommeil

Département de Pneumologie

CHU 49033 ANGERS Cedex 01

France

Fax: 33241353583

E-mail: N.Meslier@chu-angers.fr

Keywords: Impaired glucose tolerance insulin resistance

obstructive sleep apnoea syndrome

type-2 diabetes

Received: October 12002

Accepted after revision: February 272003
Obstructive sleep apnoea syndrome (OSAS) is a common disorder characterised by frequent episodes of apnoea and hypopnoea during sleep, and excessive daytime sleepiness. Its prevalence is estimated at $1-10 \%$ among middle-aged males [1-3]. Obesity is very common in patients with OSAS [4]. Excess weight in adults is clearly associated with increased incidence of type- 2 diabetes and impaired glucose tolerance (IGT) [5-7]. A high prevalence of type-2 diabetes and IGT may therefore be expected in patients with OSAS who are usually overweight and $>40$ yrs of age. These metabolic conditions may account for the cardiovascular morbidity and mortality associated with OSAS [8-10].

Insulin resistance, as indicated by an impaired biological response to insulin [11], has been implicated in the pathogenesis of a metabolic syndrome known as "insulin-resistance syndrome", which is generally accepted to comprise hyperinsulinaemia, glucose intolerance, dyslipidaemia, central obesity and hypertension [12]. Many subjects with OSAS have central obesity and other features of this metabolic syndrome. Furthermore, there is evidence that insulin resistance predisposes to cardiovascular disease [12-14]. Previous studies on the relationship between insulin resistance and OSAS [15-18] and on the effect of continuous positive airway pressure (CPAP) treatment on insulin resistance $[19,20]$ have yielded conflicting results.

The aim of this study was to evaluate the frequency of type2 diabetes and IGT in a large clinic-based male population with various degrees of sleep apnoea, and to analyse the relationship between OSAS and glucose-insulin metabolism.
Patients and methods

\section{Patients}

The study was conducted over 3 yrs between 1998-2000. Consecutive male subjects referred to the sleep laboratory for snoring and suspected OSAS were recruited for the study. The exclusion criterion was the presence of morbid obesity (body mass index $(\mathrm{BMI}) \geqslant 40 \mathrm{~kg} \cdot \mathrm{m}^{-2}$ ). Fasting blood sampling is a routine procedure in the sleep laboratory and all patients included in the study gave their informed consent for an oral glucose-tolerance test (OGTT).

\section{Methods}

Standard nocturnal polysomnography was performed with recording of sleep stages (electroencephalography, chin muscles electromyography, electro-oculography), measurements of oronasal airflow, snoring, respiratory movements and oxygen saturation $\left(\mathrm{Sa}, \mathrm{O}_{2}\right)$ with a finger pulse oximeter (Biox 3740; Ohmeda, Boulder, CO, USA). Sleep stages were scored using standard criteria [21]. Apnoea was defined as cessation of airflow for $\geqslant 10 \mathrm{~s}$. Hypopnoea was defined as a $30 \%$ reduction of airflow or respiratory movements accompanied by a $3 \%$ decrease in $\mathrm{Sa}, \mathrm{O}_{2}$ and/or followed by an arousal. Using this definition for hypopnoea, the threshold of 10 apnoea and hypopnoea per hour of sleep was chosen to define OSAS. 
Patients with an apnoea/hypopnoea index (AHI) of $<10$ were classified as nonapnoeic snorers

Each patient completed a questionnaire on demographic data, sleep symptoms and medical history. Patients were asked about any medications that they were taking at the time of the study, particularly medications likely to affect insulin or glucose levels by inducing glucose intolerance or reducing insulin secretion (thiazide diuretics, centrally acting $\alpha$-blockers, $\beta$-blockers, calcium-channel blockers, corticosteroids) or by increasing insulin sensitivity (angiotensin-converting enzyme inhibitors) [22]. Patients were also asked whether they had been previously diagnosed as having diabetes mellitus and whether they were treated for their diabetes.

On the morning after the sleep study, all patients with no known diabetes underwent a 2-h OGTT after an overnight fast. After collecting a fasting blood sample, a glucose load of $75 \mathrm{~g}$ was ingested over $5 \mathrm{~min}$. A blood sample was collected $2 \mathrm{~h}$ after the test load. Blood glucose and plasma insulin concentrations were measured in each sample. Blood glucose was assessed by glucose oxidase method and plasma insulin by a standard radioimmunoassay test. Diabetes was diagnosed according to World Health Organization criteria [23], i.e. when fasting blood glucose concentration was $>7.0 \mathrm{mM}$ or when postload blood glucose was $\geqslant 11.1 \mathrm{mM}, 2 \mathrm{~h}$ after a $75 \mathrm{~g}$ glucose load. IGT was diagnosed when postload blood glucose concentration ranged between $7.0-11.1 \mathrm{mM}$. Insulin sensitivity was evaluated by the ratio of fasting glucose (G0) to fasting insulin (I0) [24].

\section{Statistical analysis}

All clinical parameters were summarised by descriptive statistics and expressed as mean \pm sEM. OSAS patients and nonapnoeic snorers were compared using an unpaired t-test for continuous parameters and the Chi-squared test for categorical parameters. The relationships between the severity of sleep-disordered breathing and glucose-insulin metabolism indices were analysed by categorising subjects without known, treated type-2 diabetes on the basis of commonly used clinical cut-off points for AHI: $\leqslant 10,10-29.9,30-49.9$ and $\geqslant 50$ events $\cdot h^{-1}$. Analysis of variance was used to determine whether metabolic variables varied according to AHI category. The relationship between blood glucose or G0/I0 and other variables was analysed by simple regression. Multiple linear regression was performed to determine the relative contribution of age, BMI, AHI, and nocturnal oxygenation to fasting and postload blood glucose and insulin sensitivity. The relationships between glucose-insulin metabolism indices and AHI were described by regression coefficients from multivariate linear analysis.

\section{Results}

During the study period, 682 consecutive male patients with BMIs $<40 \mathrm{~kg} \cdot \mathrm{m}^{-2}$ were referred to the sleep laboratory mainly by general practitioners $(44 \%)$, general physicians $(17 \%)$, respiratory physicians $(15 \%)$ and ear, nose and throat surgeons $(13 \%)$. They complained of snoring almost every night $(91 \%)$, associated with daytime hypersomnolence $(85 \%)$, witnessed apnoea $(68 \%)$ or disturbed sleep $(55 \%)$. A total of 87 patients were not included because of missing data or refusal of the OGTT. These patients were not different from the patients studied for age, BMI or AHI. Consequently, 595 male patients were analysed. The (mean \pm SEM) age was $55.6 \pm$ 0.5 yrs (median $57.0 \mathrm{yrs}$, range $21-78 \mathrm{yrs}$ ) and BMI was $30.1 \pm 0.2 \mathrm{~kg} \cdot \mathrm{m}^{-2}$ (median $29.4 \mathrm{yrs}$, range $19.8-40.0 \mathrm{yrs}$ ).
Table 1.-Comparison of characteristics in patients with and without obstructive sleep apnoea syndrome

\begin{tabular}{lccc}
\hline & AHI $<10$ & AHI $\geqslant 10$ & p-value \\
\hline Subjects n & 101 & 494 & \\
Age yrs & $50.2 \pm 1.2$ & $56.7 \pm 0.5$ & $<0.0001$ \\
BMI kg.m ${ }^{-2}$ & $27.4 \pm 0.4$ & $30.6 \pm 0.2$ & $<0.0001$ \\
Current smokers & 24 & 26 & 0.8 \\
Exsmokers $_{\text {Alcohol }>60 \text { g.day }^{-1}}$ & 45 & 46 & 0.8 \\
Hypertension $^{\#}$ & 13 & 14 & 0.9 \\
Hyperlipidaemia $^{\#}$ & 29 & 45 & 0.003 \\
Known diabetes $^{\#}$ & 10 & 21 & 0.008 \\
Newly diagnosed diabetes & 10.9 & 18.8 & $<0.0001$ \\
IGT & 3.0 & 11.3 & $<0.0001$ \\
\hline
\end{tabular}

Data are presented as mean \pm SEM or per cent unless otherwise stated. AHI: apnoea/hypopnoea index; BMI: body mass index; IGT: impaired glucose tolerance. ${ }^{\#}$ : per cent of patients on medication for hypertension, hyperlipidaemia or diabetes.

The BMI was lower than $27 \mathrm{~kg} \cdot \mathrm{m}^{-2}$ in $26.7 \%$ of patients and $\geqslant 30 \mathrm{~kg} \cdot \mathrm{m}^{-2}$ in $47.2 \%$ of patients. Some patients $(42 \%)$ were hypertensive and were treated by antihypertensive medications and $19 \%$ had hyperlipidaemia treated by medications. Current smokers comprised $26 \%$ and $14 \%$ had an alcohol intake of $>60 \mathrm{~g} \cdot \mathrm{day}^{-1}$. The mean AHI for the whole population was $42.0 \pm 1.3$. AHI was $\geqslant 10$ in 494 patients $(83.1 \%$ OSAS group) and $<10$ in 101 patients (nonapnoeic snorers).

Table 1 summarises the comparative characteristics of apnoeic patients and nonapnoeic snorers. As expected in a clinical population, OSAS patients were more overweight than nonapnoeic snorers. BMI was $>30 \mathrm{~kg} \cdot \mathrm{m}^{-2}$ in $45 \%$ of OSAS patients and $22 \%$ of nonapnoeic snorers. The prevalence of abnormal glucose tolerance (diabetes plus IGT) was $50.1 \%$ in the OSAS group and $27.8 \%$ in the nonapnoeic snorers $(\mathrm{p}=0.0002)$. The prevalence of diabetes was $30.1 \%$ in the OSAS group and $13.9 \%$ in the nonapnoeic snorers $(\mathrm{p}<0.0001)$. Diabetes had been previously diagnosed and was treated in 104 patients (93 OSAS patients and 11 nonapnoeic snorers) and previously undiagnosed diabetes was detected in 59 patients (56 OSAS patients and three nonapnoeic snorers). IGT was diagnosed in 113 patients (99 OSAS patients and 14 nonapnoeic snorers). The prevalence of IGT was $20.0 \%$ in the OSAS group and $13.9 \%$ in the nonapnoeic snorers $(\mathrm{p}<0.0001)$. Patients with known and treated diabetes were then excluded from further analysis.

To evaluate the relationship between sleep-disordered breathing and indices of metabolic function, the distribution of each variable was examined across the four AHI categories (table 2). Fasting and postload glucose and insulin levels increased with AHI. The index of insulin sensitivity showed an increasing insulin resistance with increasing AHI. Trend analysis, however, showed that the main confounding factors (age and BMI) also significantly increased with AHI (all $\mathrm{p}<0.01)$.

Simple regression analysis showed a significant correlation between postload blood glucose and age $(\mathrm{r}=0.20, \mathrm{p}<0.001)$, BMI ( $\mathrm{r}=0.36, \mathrm{p}<0.0001)$, AHI $(\mathrm{r}=0.30, \mathrm{p}<0.0001)$, mean nocturnal $\mathrm{Sa}_{2} \mathrm{O}_{2}(\mathrm{r}=-0.26, \mathrm{p}<0.0001)$ and desaturation index $(\mathrm{r}=-0.29, \mathrm{p}<0.0001)$. A significant correlation was also observed between the index of insulin sensitivity (G0/I0) and BMI $(r=0.35, p<0.0001)$, AHI $(r=0.22, p<0.0001)$, mean nocturnal $\mathrm{Sa}_{\mathrm{a}} \mathrm{O}_{2}(\mathrm{r}=-0.13, \mathrm{p}<0.0053)$ and desaturation index $(\mathrm{r}=-0.18, \mathrm{p}<0.0002)$. Multiple linear regression analysis was then performed to examine the independent associations between sleep apnoea severity, glucose tolerance and insulin sensitivity. Age, BMI, AHI, mean nocturnal $\mathrm{Sa}, \mathrm{O}_{2}$ and number 
Table 2.-Clinical, polysomnographical and metabolical data according to apnoea/hypopnoea index (AHI) categories

\begin{tabular}{|c|c|c|c|c|c|}
\hline & \multicolumn{5}{|c|}{ AHI categories } \\
\hline & $<10$ & $\geqslant 10-<30$ & $\geqslant 30-<50$ & $\geqslant 50$ & p-value \\
\hline Subjects & $90(18.3)$ & $140(28.5)$ & $79(16.1)$ & $182(37.1)$ & \\
\hline Age yrs & $49.4 \pm 1.3$ & $54.5 \pm 0.9$ & $54.6 \pm 1.3$ & $58.0 \pm 0.8$ & $<0.0001$ \\
\hline $\mathrm{BMI} \mathrm{kg} \cdot \mathrm{m}^{-2}$ & $27.0 \pm 0.4$ & $28.5 \pm 0.4$ & $29.0 \pm 0.4$ & $31.4 \pm 0.3$ & $<0.0001$ \\
\hline TST min & $348 \pm 9$ & $342 \pm 6$ & $344 \pm 8$ & $346 \pm 5$ & 0.923 \\
\hline AHI $n \cdot h^{-1}$ & $4.0 \pm 0.3$ & $19.2 \pm 0.5$ & $38.9 \pm 0.6$ & $73.1 \pm 1.2$ & $<0.0001$ \\
\hline Arousal index $n \cdot h^{-1}$ & $15.1 \pm 0.7$ & $23.9 \pm 1.0$ & $38.5 \pm 2.3$ & $61.7 \pm 1.3$ & $<0.0001$ \\
\hline Mean $S \mathrm{a}, \mathrm{O}_{2}^{\#} \%$ & $93.4 \pm 0.2$ & $92.5 \pm 0.2$ & $92.1 \pm 0.4$ & $89.3 \pm 0.4$ & $<0.0001$ \\
\hline Desaturation index $n \cdot h^{-1}$ & $4.8 \pm 0.7$ & $12.9 \pm 1.1$ & $27.3 \pm 2.2$ & $60.1 \pm 1.7$ & $<0.0001$ \\
\hline Fasting glucose mM & $5.2 \pm 0.1$ & $5.4 \pm 0.1$ & $5.4 \pm 0.1$ & $5.7 \pm 1.1$ & $<0.001$ \\
\hline Postload glucose mM & $6.3 \pm 0.2$ & $7.0 \pm 0.3$ & $7.0 \pm 0.3$ & $8.5 \pm 0.2$ & $<0.0001$ \\
\hline Fasting insulin $\mathrm{mU} \cdot \mathrm{L}^{-1}$ & $11.2 \pm 0.8$ & $14.2 \pm 0.8$ & $13.3 \pm 0.9$ & $16.8 \pm 0.9$ & $<0.0002$ \\
\hline Postload insulin $\mathrm{mU} \cdot \mathrm{L}^{-1}$ & $56.7 \pm 6.4$ & $74.3 \pm 5.7$ & $72.7 \pm 6.2$ & $102.6 \pm 5.7$ & $<0.0001$ \\
\hline Fasting G0/I0 & $0.65 \pm 0.04$ & $0.51 \pm 0.02$ & $0.53 \pm 0.03$ & $0.45 \pm 0.02$ & $<0.0001$ \\
\hline
\end{tabular}

Data are presented as $\mathrm{n}(\%)$ or mean \pm SEM unless otherwise stated. BMI: body mass index; TST: total sleep time; $S \mathrm{a}, \mathrm{O}_{2}$ : oxygen saturation; G0/I0: ratio of fasting glucose to fasting insulin. ${ }^{\#}$ : during sleep; ${ }^{\natural}$ : one-way analysis of variance.

of desaturation episodes were used as independent variables (table 3). After adjustment for age and BMI, AHI remained independently related to postload blood glucose (adjusted $\left.\mathrm{r}^{2}=0.18, \mathrm{p}<0.0001\right)$ and to the index of insulin sensitivity $(\mathrm{G} 0 / \mathrm{I} 0)$ (adjusted $\left.\mathrm{r}^{2}=0.14, \mathrm{p}<0.0001\right)$. Conversely, BMI was the only factor influencing fasting glucose (adjusted $\mathrm{r}^{2}=0.13, \mathrm{p}<0.0001$ ). A large number of patients $(n=246)$ were taking medications likely to affect insulin or glucose levels at the time of the study. The authors therefore introduced a variable into the regression model to define patients with or without such treatment. Introduction of this treatment variable did not change the relationship between postload blood glucose or G0/I0 and the other variables (age, BMI, AHI, mean nocturnal $\mathrm{Sa}, \mathrm{O}_{2}$ and desaturation index). After adjustment for medications, postload blood glucose and G0/I0 remained independently related to age, BMI, AHI (adjusted $\mathrm{r}^{2}=0.18, \mathrm{p}<0.0001$ for postload blood glucose; adjusted $\mathrm{r}^{2}=0.13, \mathrm{p}<0.0001$ for $\mathrm{G} 0 / \mathrm{I} 0)$.

\section{Discussion}

This cross-sectional study in a clinic-based sample of mildly obese (median BMI $29.4 \mathrm{~kg} \cdot \mathrm{m}^{-2}$ ) males with a wide range of AHI shows two major findings. First, abnormal glucose metabolism, i.e. IGT and type- 2 diabetes, is relatively common in patients with an AHI of $\geqslant 10$. Diabetes was previously undiagnosed in $40 \%$ of diabetic patients and all cases of IGT were newly diagnosed during the study. Secondly, the AHI is independently related to glucose metabolism and insulin sensitivity after adjusting for confounding variables.

Insulin sensitivity was evaluated using the OGTT instead of the euglycaemic insulin clamp that is considered to be the gold standard [25]. However, this method is invasive and labourintensive and is difficult to incorporate at a population level. Insulin sensitivity indices derived from the OGTT are strongly correlated with measures of insulin action determined by the euglycaemic insulin clamp [26].

The frequencies of type-2 diabetes and IGT in the OSAS patients (30.1 and $20 \%$, respectively) were higher than the prevalence of these clinical disorders in the general population. In France, the prevalence of type- 2 diabetes is estimated to be $3.5-8.6 \%$ between the ages of $45-74$ yrs [27]. Such a high prevalence of type- 2 diabetes in OSAS patients $(31.4 \%)$ has been suggested by KATSUMATA et al. [28] in a smaller population $(\mathrm{n}=35)$, whereas LEVINSON et al. [29] found a prevalence of type- 2 diabetes and IGT of 11 and $30 \%$, respectively, in 45 males with OSAS. However, only $50 \%$ of their patients underwent an OGTT. An important clinical finding of the present study is that type-2 diabetes was newly diagnosed in $40 \%$ of the diabetic patients. This is in agreement with epidemiological data on the prevalence of type- 2 diabetes in general populations showing that there is almost one unknown case of type-2 diabetes for each known case [30].

Age and obesity are two important factors contributing to the development of glucose intolerance and insulin resistance. Previous studies on the relative contribution of sleep-disordered breathing and obesity to impaired glucose-insulin metabolism have yielded conflicting results depending on the marker used to define insulin resistance and the study population.

In a study of 50 healthy asymptomatic subjects ( 34 females), $30 \%$ of whom had a sleep-disordered breathing index of $\geqslant 10$ on respiratory monitoring with a Mesam-IV device (MAP, Munich, Germany), STOOHs et al. [16] did not find any

Table 3. - Multiple linear regression models for fasting and postload blood glucose, and insulin sensitivity

\begin{tabular}{|c|c|c|c|c|c|c|}
\hline \multirow[t]{2}{*}{ Independent variables } & \multicolumn{2}{|c|}{ Fasting blood glucose } & \multicolumn{2}{|c|}{ Postload blood glucose } & \multicolumn{2}{|l|}{ G0/I0 } \\
\hline & $\beta(95 \% \mathrm{CI})$ & p-value & $\beta(95 \% \mathrm{CI})$ & p-value & $\beta(95 \% \mathrm{CI})$ & p-value \\
\hline Age & $-0.003(-0.012-0.005)$ & 0.44 & $0.029(0.006-0.052)$ & 0.0129 & $0.003(0.0003-0.005)$ & 0.029 \\
\hline BMI & $0.071(0.048-0.094)$ & 0.0001 & $0.176(0.113-0.239)$ & 0.0001 & $-0.022(-0.028-0.015)$ & 0.0001 \\
\hline AHI & $-0.002(-0.007-0.004)$ & 0.52 & $0.021(0.006-0.036)$ & 0.0067 & $-0.002(-0.004-0.001)$ & 0.0067 \\
\hline Mean $\mathrm{Sa}_{2} \mathrm{O}_{2}{ }^{\#}$ & $-0.016(-0.044-0.012)$ & 0.27 & $-0.074(-0.149-0.001)$ & 0.0518 & $0.002(-0.006-0.010)$ & 0.62 \\
\hline Desaturation index & $0.004(-0.003-0.010)$ & 0.27 & $-0.009(-0.026-0.009)$ & 0.32 & $0.002(-0.00009-0.003)$ & 0.063 \\
\hline
\end{tabular}

G0/I0: ratio of fasting glucose to fasting insulin; CI: confidence interval; BMI: body mass index; AHI: apnoea/hypopnoea index; $S \mathrm{a}, \mathrm{O}_{2}$ : oxygen saturation. ${ }^{\#}$ : during sleep. 
relationship between insulin resistance and sleep-disordered breathing after adjusting for BMI. The small sample size, the small range of AHI and the use of a simplified monitoring technique may limit the conclusions of this study. Another study [20] reported no relationship between sleep-disordered breathing and insulin resistance, as the authors did not find any effect of CPAP treatment on glucose-insulin metabolism in sleep apnoeic patients. The very small sample size and the short duration of CPAP treatment and the lack of information concerning actual use of the CPAP equipment may also limit the conclusions of this study.

The present results confirm some previous clinic-based studies on smaller samples suggesting an independent relationship between sleep apnoea and abnormal glucose tolerance [15, 17-19]. Three studies on very small samples of patients have suggested a link between sleep-disordered breathing and impaired glucose-insulin metabolism. In a series of 18 obese patients including one known diabetic on medication, TIIHONEN et al. [17] found a relationship between insulin-resistance indices and desaturation index, but not AHI. VGONTAS et al. [18] found that fasting insulin and blood glucose were higher in 14 obese patients with OSAS than in 11 obese subjects without sleepdisordered breathing. However, they did not analyse the relationship between sleep-disordered breathing and fasting blood glucose and insulin on this small sample. The improvement in insulin responsiveness, demonstrated by BROOKS et al. [19] in nine type-2 diabetic patients with OSAS after treatment with CPAP, also suggested that sleep-disordered breathing may affect glucose-insulin metabolism. In a larger sample of 261 males referred for suspected sleep apnoea, STROHL et al. [15] measured fasting serum insulin and fasting blood glucose and found a significant relationship between fasting insulin and AHI, independently of BMI. However, they did not analyse insulin sensitivity and did not perform OGTTs, and therefore probably missed a large number of cases of impaired glucose metabolism.

In a recent study on a community sample of 150 healthy but mildly obese males, 57 of whom had an AHI of $<5$, PUNJABI et al. [31] found that sleep-disordered breathing was associated with IGT and insulin resistance, independently of obesity. They highlighted the relationship between IGT or insulin sensitivity and the severity of oxygen desaturation. The study of IP et al. [32] conducted in an Asian sample, including both patients referred for suspected sleep apnoea and for a community-based prevalence study, also found that sleep-disordered breathing has an independent adverse effect on insulin resistance analysed by fasting insulin and an index of insulin resistance. The current study is the first study conducted in a large European sample of subjects with disease states. It concerned a consecutive clinic-based sample in which patients were referred by general practitioners and physicians. The most common reason for referral to the sleep unit was snoring associated with either excessive daytime sleepiness, disturbed nocturnal sleep or insomnia. None of these patients were specifically referred for assessment of disorders of glucose metabolism associated with clinical signs of OSAS. The clinical characteristics and associated comorbidity of the patients did not differ from those of previously reported large series of males with suspected OSAS [4, 10, 15]. The large population was composed of patients consecutively recruited over a long period ( $3 \mathrm{yrs})$, thereby reducing the risk of selection bias. The strong points of the study were that it included a large sample size with a wide range of AHIs (0-113), BMIs (19.8-40 $\left.\mathrm{kg} \cdot \mathrm{m}^{-2}\right)$ and ages (21-78 yrs) and that it excluded patients with morbid obesity and investigated all medications likely to affect glucose or insulin metabolism.

Community-based studies on the prevalence of sleepdisordered breathing have already shown that sleep apnoea is underdiagnosed in females compared with males [33]. In this population, as in other clinical populations, the male:female ratio for diagnosed apnoea is 8:1 compared with $3: 1$ in populationbased studies [3]. To avoid this sex bias, females were not included in this study. The authors speculate that the metabolic consequences related to sleep apnoea may be similar in females for a similar severity of disease. The study by IP et al. [32] did not demonstrate any evidence of a different susceptibility to insulin resistance in males and females with the same degree of obesity and sleep-disordered breathing.

Hypoxia has already been shown to be associated with impaired glucose metabolism. PUNJABI et al. [31] found that the degree of hypoxaemia was related to glucose intolerance. In the present study, although univariate analysis showed a relationship between mean nocturnal $\mathrm{Sa}_{2} \mathrm{O}_{2}$ or desaturation index and postload blood glucose and insulin sensitivity, AHI was the only polygraphic parameter independently related to glucose-insulin metabolism on multiple linear regression analysis. The highly significant correlation between AHI and desaturation index $(\mathrm{r}=0.84, \mathrm{p}<0.0001)$ or mean nocturnal $\mathrm{Sa}_{\mathrm{a}} \mathrm{O}_{2}(\mathrm{r}=0.50$, $\mathrm{p}<0.0001)$ may explain why only AHI emerged from multivariate analysis, whereas the indices of nocturnal hypoxaemia failed to reach significance. Other mechanisms might explain the association between sleep-disordered breathing and impaired glucose-insulin metabolism. OSAS is associated with an increase in nocturnal sympathetic activity [34], which may also facilitate the development of glucose intolerance and insulin resistance.

To conclude, in a large clinic-based population of males with obstructive sleep apnoea syndrome, a high frequency of undiagnosed type-2 diabetes and impaired glucose tolerance was found. The study also showed an independent relationship between sleep-disordered breathing and impaired glucoseinsulin metabolism. Glucose intolerance may contribute to the cardiovascular morbidity and mortality associated with obstructive sleep apnoea syndrome.

\section{References}

1. Lavie P. Incidence of sleep apnea in a presumably healthy working population: a significant relationship with excessive daytime sleepiness. Sleep 1983; 6: 312-318.

2. Gislason T, Almqvist M, Eriksson G, Taube A, Bowman G. Prevalence of sleep apnea syndrome among Swedish men an epidemiological study. J Clin Epidemiol 1988; 41: 571576.

3. Young T, Palta M, Dempsey J, Skatrud J, Weber S, Badr S. The occurrence of sleep disordered breathing among middleaged adults. $N$ Engl J Med 1993; 328: 1230-1235.

4. Guilleminault C. Clinical features and evaluation of obstructive sleep apnoea. In: Kryger MH, Roth T, Dement WC, eds. Principles and Practice of Sleep Medicine. Philadelphia, W.B. Saunders, 1989; pp. 552-558.

5. Medalie JH, Papier CM, Goldbourt U, Herman JB. Major factors in the development of diabetes mellitus in 10,000 men. Arch Intern Med 1975; 135: 811-817.

6. Skarfors ET, Selinus I, Lithell HO. Risk factors for developing non-insulin dependent diabetes: a 10 year follow up of men in Uppsala. BMJ 1991; 303: 755-760.

7. Harris M, Hadden W, Knowler W. Prevalence of diabetes and impaired glucose tolerance and plasma glucose levels in US population aged 24-74. Diabetes 1987; 36: 523-528.

8. He J, Kryger MH, Zorick FJ, Conway W, Roth T. Mortality and apnoea index in obstructive sleep apnoea: experience in 385 male patients. Chest 1988; 94: 9-14.

9. Hung J, Whitford EG, Parsons RW, Hillman DR. Association of sleep apnoea with myocardial infarction in men. Lancet 1990; 336: 261-264.

10. Partinen M, Guilleminault C. Daytime sleepiness and vascular 
morbidity at seven-year follow-up in obstructive sleep apnoea patients. Chest 1990; 97: 27-32.

11. American Diabetes Association. Consensus Development Conference On Insulin Resistance. Diabetes Care 1998; 21: $1-511$.

12. Reaven G. Role of insulin resistance in human disease. Banting Lecture. Diabetes 1988; 37: 1595-1607.

13. Zavaroni I, Bonora E, Pagliara M, et al. Risk factors for coronary artery disease in healthy persons with hyperinsulinemia and normal glucose tolerance. $N$ Engl $\mathrm{J}$ Med 1989; 320: 702-706.

14. Lindahl B, Asplund K, Hallmans G. High serum insulin, insulin resistance and their associations with cardiovascular risk factors. The northern Sweden MONICA population study. J Int Med 1993; 234: 263-270.

15. Strohl KP, Novak RD, Singer W, et al. Insulin levels, blood pressure and sleep apnoea. Sleep 1994; 17: 614-618.

16. Stoohs RA, Facchini F, Guilleminault C. Insulin resistance and sleep-disordered breathing in healthy humans. Am J Respir Crit Care Med 1996; 154: 170-174.

17. Tiihonen M, Partinen M, Närvänen S. The severity of obstructive sleep apnoea is associated with insulin resistance. J Sleep Res 1993; 2: 56-61.

18. Vgontas AN, Papanicolaou DA, Bixler EO, et al. Sleep apnea and daytime sleepiness and fatigue: relation to visceral obesity, insulin resistance and hypercytokinemia. J Clin Endo Metab 2000; 85: 1151-1158.

19. Brooks B, Cistulli PA, Borkman M, et al. Obstructive sleep apnoea in obese non insulin-dependent diabetic patients: effect of continuous positive airway pressure treatment on insulin responsiveness. J Clin Endocrinol Metab 1994; 79: 1681-1685.

20. Smurra M, Philip P, Taillard J, Guilleminault C, Bioulac B, Gin H. CPAP treatment does not affect glucose metabolism in sleep apneic patients. Sleep Med 2001; 2: 207-213.

21. Rechtschaffen A, Kales A, eds. A Manual of Standardized Terminology and Scoring System for Sleep Stages of Human Subjects. National Institutes for Health publication no. 204. Bethesda, National Institute of Neurological Diseases and Blindness, 1968.

22. Pandit MK, Burke J, Gustafson AB, Minocha A, Pecris AN. Drug-induced disorders of glucose tolerance. Ann Int Med 1993; 118: 529-539.

23. World Health Organization. Definition, diagnosis and classification of diabetes mellitus and its complications. Report of WHO consultation. Geneva, WHO/NCD/NCS/ 99.2, 1999.

24. Matsuda M, DeFronzo RA. In vivo measurement of insulin sensitivity in humans. In: Draznin B, Rizza R, eds. Clinical Research in Diabetes and Obesity. I. Methods, Assessment and Metabolic Regulation. Totowa, Humana Press, 1997; pp. 23-65.

25. DeFronzo RA, Tobin JD, Andres R. Glucose clamp technique method for quantifying insulin secretion and resistance. Am J Physiol 1979; 237: E214-E223.

26. Matsuda M, DeFronzo RA. Insulin sensitivity indices obtained from oral glucose tolerance testing: comparison with the euglycemic insulin clamp. Diabetes Care 1999; 22: $1462-1470$

27. Delcourt C, Papoz L. Le Diabète et ses Complications dans la Population Française. [Diabetes and its Complications in the French Population]. Paris, Editions INSERM, 1996.

28. Katsumata K, Okada T, Miyao M, Katsumata Y. High incidence of sleep apnoea syndrome in a male diabetic population. Diabetes Res Clin Prac 1991; 13: 45-52.

29. Levinson PD, McGarvey ST, Carlisle CC, Eveloff SE, Herbert PN, Millman RP. Adiposity and cardiovascular risk factors in men with obstructive sleep apnoea. Chest 1993; 103: 1336-1342.

30. World Health Organization. Diabetes Mellitus. Technical Report Series no. 727. Geneva, World Health Organization, 1985.

31. Punjabi NM, Sorkin JD, Katzel LI, Goldberg AP, Schwartz AR, Smith PL. Sleep-disordered breathing and insulin resistance in middle-aged and overweight men. Am J Respir Crit Care Med 2002; 165: 677-682.

32. Ip MS, Lam B, Ng MM, Lam WK, Tsang KW, Lam KS. Obstructive sleep apnea is independently associated with insulin resistance. Am J Respir Crit Care Med 2002; 165: 670-676.

33. Young T, Hutton R, Finn L, Badr S, Palta M. The gender bias in sleep apnea diagnosis: Are women missed because they have different symptoms? Arch Intern Med 1996; 156: 2445-2451.

34. Somers VK, Dyken ME, Clary MP, Abboud FM. Sympathetic neural mechanisms in obstructive sleep apnea. J Clin Invest 1995; 96: 1897-1904. 